\title{
Correction: All-Cause Mortality of Low Birthweight Infants in Infancy, Childhood, and Adolescence: Population Study of England and Wales
}

The PLOS Medicine Staff

\section{Notice of Republication}

This article was republished on May $19^{\text {th }}, 2016$ to correct poor figure quality in the PDF version, which was introduced during the typesetting process. The publisher apologizes for these issues with the figure quality. Please download this article again to view the updated version.

\section{Reference}

1. Watkins WJ, Kotecha SJ, Kotecha S (2016) All-Cause Mortality of Low Birthweight Infants in Infancy, Childhood, and Adolescence: Population Study of England and Wales. PLoS Med 13(5): e1002018. doi: 10.1371/journal.pmed.1002018 PMID: 27163787

\section{G openaccess}

Citation: The PLOS Medicine Staff (2016) Correction: All-Cause Mortality of Low Birthweight Infants in Infancy, Childhood, and Adolescence: Population Study of England and Wales. PLoS Med 13(6): e1002069. doi:10.1371/journal.pmed.1002069

Published: June 15, 2016

Copyright: @ 2016 The PLOS Medicine Staff. This is an open access article distributed under the terms of the Creative Commons Attribution License, which permits unrestricted use, distribution, and reproduction in any medium, provided the original author and source are credited. 